\title{
Relationship between photochemical efficiency (JIP-Test Parameters) and portable chlorophyll meter readings in papaya plants
}

\section{Fernanda Assumpção Castro ${ }^{1}$, Eliemar Campostrini ${ }^{1 *}$, Alena Torres Netto ${ }^{2}$, Leandro Hespanhol Viana ${ }^{1}$}

${ }^{1}$ Universidade Estadual do Norte Fluminense Darcy Ribeiro (UENF) / Centro de Ciências e Tecnologias Agropecuárias / Setor de Fisiologia Vegetal, Av Alberto Lamego, 2000, CEP: 28013620, Campos - Rio de Janeiro - Brazil,

${ }^{2}$ Universidade Estadual do Norte Fluminense Darcy Ribeiro (UENF) / Centro de Biociências e Biotecnologias Agropecuárias/ Laboratório de Biologia Celular e Tecidual, Av. Alberto Lamego, 2000, Campos dos Goytacazes, RJ, Brazil, 28013-620

*Corresponding author: fax (55 22) 27397191 e tel: (55 22) 27397105, e-mail: campostenator@gmail.com Received: 17 May 2011; Accepted: 27 January 2012

\section{ABSTRACT}

The Portable Chlorophyll Meter (PCM) is used to estimate the total chlorophyll and leaf nitrogen content of various species. Since there is a relationship between the chlorophyll concentration and the photochemical efficiency, a relationship can also be established between the PCM readings and some fluorescence variables to provide information on photosystem II (PSII) structure and activity. Papaya (Carica papaya L.) plants ['Sunrise Solo' (leaves with intense green coloring) and 'Golden' cultivars (leaves with yellowgreen coloring) were grown in a greenhouse with $30 \%$ interception of photosynthetically active photon flux density. The plants were cultivated in 15L plastics pots. Ninety to 100 days after planting the older leaves turned yellow and the chlorophyll fluorescence variables and PCM readings were measured. At low PCM values (less than 30 to 'Sunrise Solo' and less than 20 to 'Golden') the PSIl structure and activity were damaged, which is likely related to a reduction in the numbers of active reaction centers $\left(\mathrm{RC} / \mathrm{CS}_{0}\right)$. At higher PCM values the chlorophyll a fluorescence variables (ABS/RC, $\mathrm{DI}_{0} / \mathrm{RC}, \mathrm{TR}_{0} / \mathrm{CS}_{0}$ e ET/ $/ \mathrm{CS}_{0}$ ) that are related to PSIl structure and activity PSII were not responsive. These results indicated that the effects of chlorophyll content measured by PCM on the photochemical phase of photosynthesis evaluated by chlorophyll fluorescence occur after the degradation of chlorophyll molecules is initiated. In papaya the Portable Chlorophyll Meter (SPAD-502) was shown to be suitable for diagnosis of PSIl energy distribution under $\mathrm{N}$ stress and senescence.

Keywords: Carica papaya, L., fluorescence, JIP-Test, Chlorophyll

Abbreviations: PCM: portable chlorophyll meter; SPAD-502: soil plant analysis development; PSIl: photosystem II; PAPFD: photosynthetically active photon flux density; ABS: absorbance; chl: chlorophyll; CS: cross-section; RC: reaction centre; DI: dissipation; PEA: Plant Efficiency Analyser; Qa: primary electron acceptor of PS II; TR: trapping; LED: Light emitting diode; LHCP II: light-harvesting chlorophyll binding proteins. 


\section{INTRODUCTION}

Obtaining new nondestructive technologies to study plant ecophysiology may lead to greater understanding of all the physiological processes. Further, when it becomes possible to carry out experiments and field studies with these technologies, users may be able to solve crop-related problems quickly, with less expense and without destroying the sampled material. Examples of these technologies are the PEA model of non modulated fluorimeter (Plant Efficiency Analyser, Hansatech Instruments Ltd., King's Lynn, Norfolk, UK) and the Portable Chlorophyll Meter (PCM) (SPAD -502; Soil Plant Analysis Development, Minolta Camera Co. Ltd.). These technologies has fast, nondestructive measuring techniques and can be used under field conditions and permit an excellent assessment of the plant physiological process (Strasser et al., 1999; Kapoti et al., 2003).

Several papers have been published on the theoretical base and ecophysiological applications related to fluorescence (Krause and Weis, 1991; Mohammed et al., 1995, Schreiber et al., 1998, Baker, 2008). According to Krause and Weis (1991), measuring fluorescence can be considered as a complementary measurement of photosynthesis. Fluorescence emission shows the level of excitation energy in the pigment/protein complexes, the energy that controls photosynthesis (Scholes and Horton, 1993). In addition, fluorescence can be a very powerful tool to study photosynthetic performance, especially when coupled with other noninvasive measurements such as absorption spectroscopy, gas analyses, and infrared thermometry (Baker, 2008). Detailed information can be obtained through fluorescence on the structure, energy distribution and function of the photosynthesis operation, especially for PSII (Strasser et al., 2000). But fluorescence data can be better interpreted using the assessor test, the JIP-Test (Strasser and Strasser, 1995). By using the non-modulated fluorimeter Strasser and Strasser (1995), an optimized interpretations of fast fluorescence kinetics $\left(\mathrm{F}_{0}=50 \mu \mathrm{s} ; \mathrm{Fj}=2 \mathrm{~ms}\right.$ and $\left.\mathrm{Fi}=30 \mathrm{~ms}\right)$ that lie between the two extremes of the fluorescence intensity $\left(\mathrm{F}_{0}=50 \mu \mathrm{s}\right.$ and $\mathrm{Fm}$ $=300 \mathrm{~ms}$ ) can be obtained. The JIP-Test is based on the theory of energy flow in biomembranes, which uses ratios to obtain variables that explain the energy flow through PS II (Strasser and Strasser, 1995). By measuring variables associated with structural and functional aspects of PSII, the JIP-Test can be used to indicate the vitality of the plant material analyzed (Strasser et al., 2000).

Since fluorescence can indicate the status and changes in the PSII structure and activity (Strasser et al., 2000) physically located in the thylakoids, the degradation of these membranes can be expected to modify fluorescence emission. Changes in photosynthetic metabolism, which can be induced by many biotic and abiotic factors, will modify fluorescence emission kinetic characteristics of plants (Baker and Rosenqvist, 2004). The biotic and abiotic factors can promote senescence due this process cause loss of chlorophylls pigments (Hendry and Price, 1993, Brown et al., 1991). Senescence represents the final stage of leaf development, and is characterized by the transition from nutrient assimilation to nutrient remobilization (Feller and Fischer, 1994; Masclaux et al., 2000). In mesophyll cells, during the senescence chloroplasts are dismantled in an early phase of senescence, while mitochondria remain functional (Hortensteiner and Feller, 2002). Up to $75 \%$ of the nitrogen present in mesophyll cells is located in the chloroplasts (Peoples and Dalling, 1988), and most of nitrogen content of chloroplast is integrated in the thylakoidbound apoproteins of chlorophyll. Then, the morphological analysis of senescing chloroplasts reveals dramatic changes of the thylakoid membrane system (Hortensteiner and Feller, 2002).

The PCM, has been used intensively to estimate chlorophyll content for nutritional assessment related to nitrogen because there is a high positive correlation between nitrogen and chlorophyll contents (Evans, 1989). The PCM uses two LEDs that emit narrow band radiation at $650 \mathrm{~nm}$ (red) and $940 \mathrm{~nm}$ (infrared) to the leaf surface. The chlorophyll complex absorbs radiation at $650 \mathrm{~nm}$ and does not absorb at 940nm (Hendry and Price 1993). The chlorophylls and carotenoids also absorb in the blue region $(\lambda=450 \mathrm{~nm})$ so absorption only in the red eliminates carotenoid interference. The absorbance at $940 \mathrm{~nm}$ standardizes the effects of leaf thickness, water content and other factors that may affect photon passage through the leaf. The PCM value (on a scale from 1 to 100 ) is calculated from the difference in optical density between the two wavelengths measured by a photodiode detector located opposite the emission source. The portion 
of the leaf sampled is located between source and the detector. When using PCM to estimate leaf chlorophyll content, calibration curves must be made for the species/ cultivar or variety studied that correlate PCM values with the true concentration of these pigments, determined by biochemical analyses (Wellburn, 1994).

In rice, Kumagai et al. (2009) correlated PCM readings with some photosynthetic parameters, suggesting that the PCM readings are an indirect indication of the photosynthetic capacity in the flag leaves. In Amaranthus vlitus, there was a linear correlation between PCM readings and some physiological parameters of the leaves, such as photosynthesis, transpiration, and stomatal conductance. (Kapotis et al., 2003).

When papaya undergoes some type of stress, whether water shortage or especially nitrogen deficiency, yellowing starts on the leaves at the base of the trunk and spreads to the tip of the stalk. A simple methodology is needed to determine the level of damage to photosynthesis due to the range of abiotic stresses that cause the senescence in papaya plants. The objective of this study was to determine if there was a relationship between PCM values and PSII performance obtained with the PEA non-modulated fluorimeter using the Biolyzer software (with the JIP-Test) on two Carica papaya L. genotypes ('Sunrise Solo' and 'Golden') that have contrasting chlorophyll content.

\section{MATERIALS AND METHODS}

The experiment was conducted in a greenhouse with $30 \%$ interception of the photosynthetically active photon flux density (PAR) at the Plant Physiology Sector, LMVG, at the Northern Rio de Janeiro State University, Campos dos Goytacazes, RJ (21045' S; 41017' W) from June to November. Two Carica papaya L. genotypes were used: 'Sunrise Solo' has intense green covering and 'Golden' has yellow-green coloring. From 15th June until 1st August, six plastic $15 \mathrm{~L}$ pots, containing soil with the addition of cow manure in the ratio of $3: 1$, were sown daily with four seeds in each pot, alternating the genotype sown, to obtain twenty eight plants per genotype at ninety days after each sowing (DAS) (3rd -4th green leaves; and 6th -7th green leaves) and twenty six plants per genotype at hundred DAS of each plant (3rd -4th green leaves; and 6th -7th senescent leaves). After hundred DAS, there was intense chlorosis in older leaves (6th-7th leaves, PCM reading $<30$ ), due to $\mathrm{N}$ deficiency which reduced total chlorophyll concentration. The $\mathrm{N}$ deficiency caused senescence of leaves.

The plants were thinned when they were $6 \mathrm{~mm}$ tall, irrigated daily and weeds were controlled manually. Throughout the experiment, variables such as temperature, relative humidity and PAR were measured (WatchDog 450, Spectrum Technologies, Illinois, USA), at hourly intervals. The mean temperature was $20.8 \pm 3.4^{\circ} \mathrm{C}$, and the mean of the relative humidity was $82 \pm 13 \%$. The maximum PAR was $1000 \mu$ moles $\mathrm{m}^{-2} \mathrm{~s}^{-1}$. The chlorophyll fluorescence was measured at $730 \mathrm{~h}$., at ninety and hundred DAS using the PEA non-modulated fluorimeter (Hansatech Instruments, England). The distal extremity of the central vein of the leaf blade of the $3^{\text {rd }}$ or $4^{\text {th }}$ leaf (mature leaves) and the $6^{\text {th }}$ or $7^{\text {th }}$ leaf (old leaves) counted from the top were measured. Prior to measurement, 3 leafclips were attached to maintain the leaf area in the dark for thirty minutes so that the reaction centers acquired the open condition (oxidized Qa) (Bòlhar-Nordenkampf et al., 1989). After dark adjustment, illumination was supplied by a set of 6 LEDs at $650 \mathrm{~nm}$ with homogeneous $3000 \mu$ moles $\mathrm{m}^{-2}$ $\mathrm{s}^{-1}$ illumination on an area of $4 \mathrm{~mm}$ diameter per leafclip, using 5 fluorescence levels [F1 $(t=50 \mu \mathrm{s}), F 2(t=100 \mu \mathrm{s})$, F3 $(t=300 \mu \mathrm{s}), F 4(t=2 \mathrm{~ms}), F 5(t=30 \mathrm{~ms})]$ given by the PEA fluorimeter (Strasser et al. 2000). The following variables were measured and calculated using the Biolyzer software (R.J. Strasser, University of Geneva, Laboratory of Bioenergetics, Switzerland) of the JIP-Test (indicators of the performance of the photochemical process of photosynthesis): 1) $A B S / R C$ ratio (the total number of photons absorbed by chl-molecules of all reaction centers (RCs) divided by the total number of active RCs. It is influenced by the ratio of active/inactive RCs); 2) $T_{0} / R C$ (the maximal rate by which an exciton is trapped by the $\mathrm{RC}$ resulting in the reduction of $\mathrm{Qa}$ ); 3 ) $\mathrm{DI}_{0} / \mathrm{RC}$ (The ratio of the total dissipation of untrapped excitation energy from all $\mathrm{RCs}$ with respect to the number of active RCs. Dissipation occurs as heat, fluorescence and energy transfer to other systems. It is influenced by the ratio of active/inactive RCs), 4) $\mathrm{TR}_{0} / \mathrm{CS}_{0}$ (the maximal trapping rate of an exciton that will lead to Qa reduction measured over a cross-section of active and inactive RCs), 5) $\mathrm{ET}_{0} / \mathrm{CS}_{0}$ (the reoxidation of 
reduced Qa via electron transport over a cross-section of active and inactive RCs) and 6) $\mathrm{RC} / \mathrm{CS}_{0}$ (concentration of the active reaction centres) (Force et al., 2003).

After measuring chlorophyll fluorescence, ten PCM readings were taken in the region where the PEA leafclips had been placed, totaling thirty readings per leaf. A mean PCM leaf value was calculated $(\mathrm{N}=30)$.

After removing the leaf disc on the same side where the chlorophyll fluorescence was measured, approximately 40 readings was taken using the PCM meter (SPAD-502, Minolta Camera Company, Japan) on the remaining part of the leaf blade. Afterwards, this part of the leaf was placed in the paper bags, taken to forced ventilation chamber at $25^{\circ} \mathrm{C}$ for 72 hours, weighed, squashed in a porcelain mortar (due to small amount of the material) and stored in the hermetically sealed flasks. Sulfuric digestion was performed on the ground material stored in sealed flasks and then the organic $\mathrm{N}$ concentration was determined on the leaf dry matter using the method by Nessler (Jackson, 1965).

\section{RESULTS AND DISCUSSION}

The structure and function of PSII can be quantified through the JIP test using the polyphasic fluorescence

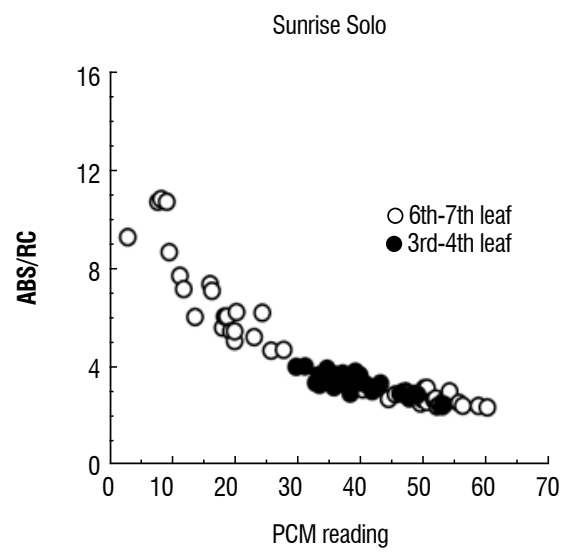

transients (Strasser et al., 1999, Strasser et al., 2000). We established the relationship between PCM values and PSII photochemical using the JIP test derived from the polyphasic rise of transient fluorescence. The calculated functional parameters are the specific (per reaction center, RC) and phenomenological (per cross section of the sample, CS) energy fluxes for absorption (ABS), trapping (TR), and electron transport (ET) (Lu et al., 2001).

The relationship between PCM and ABS/RC (Figure 1) and $\mathrm{TR}_{0} / \mathrm{RC}$ (Figure 2) refer to the energy absorbed by the chlorophyll molecules in the PSII antenna system (ABS), to the reduction in capacity of the Qa by the absorbed energy $(\mathrm{TR})$, in relation to the quantity of active reaction centers (RC), respectively (Strasser etal., 2000). According to these authors, these variables can show the PSII structure and activity, and the reduction in the PCM readings caused increases in the $A B S / R C$ ratio (Figure 1) and $T_{0} / R C$ (Figure 2). The response was the same for both the genotypes studied.

Increases in $A B S / R C$ and $T R_{0} / R C$ were caused by a reduction in the quantity of active reaction centers of the senescent old leaves (Figure 3). According to Strasser et al. (2000), the $\mathrm{RC} / \mathrm{CS}_{0}$ ratio (Figure 4) measures the quantity of active reaction centers (functional reaction centers). Thus, in both papaya genotypes the senescent leaves (PCM reading $<30$ ) showed intense reduction of active reaction centers.

cultivated in a greenhouse. The open circles with reduced PCM readings $(<30)$ refer the senescent 6 th -7 th leaves. 
Sunrise Solo

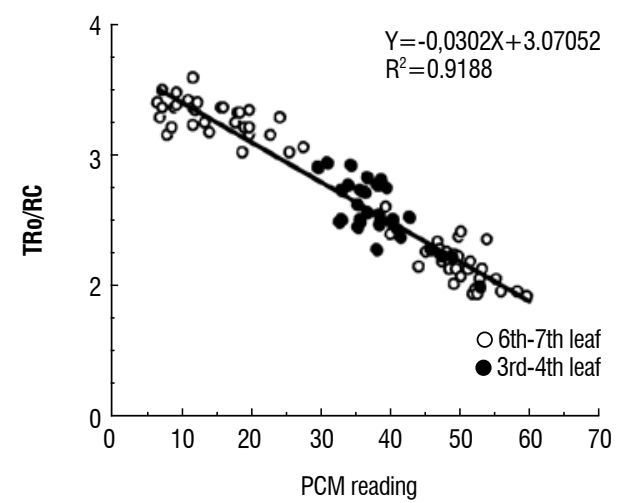

Golden

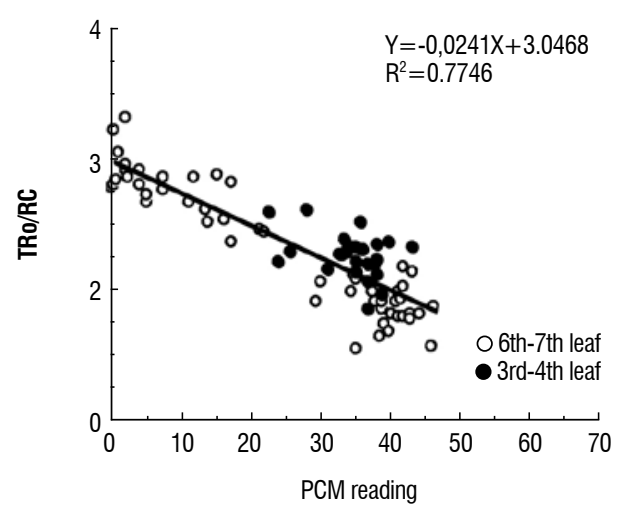

Figure 2. Relationship between the $\mathrm{TR}_{0} / \mathrm{RC}$ (quantity of energy captured (reduced Qa) per unit of active reaction center and the PCM reading), on Sunrise Solo and Golden papaya plants cultivated in a greenhouse. The open circles with reduced PCM readings $(<30)$ refer the senescent 6 th -7 th leaves.

Sunrise Solo

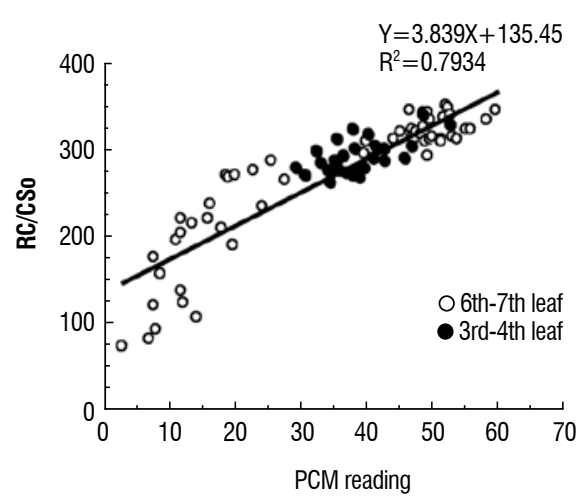

Golden

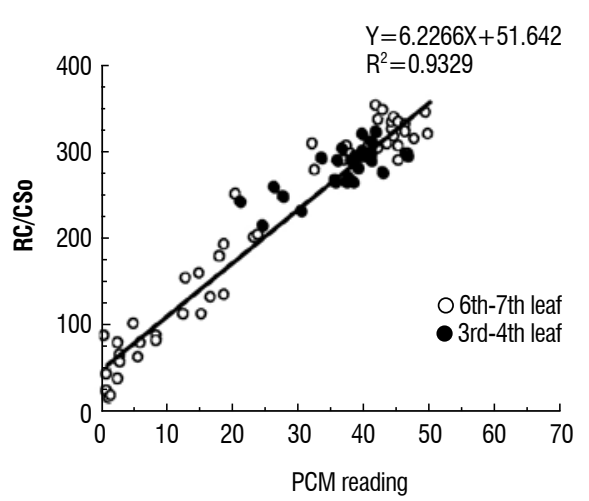

Figure 3. Relationship between the $\mathrm{RC} / \mathrm{CS}_{0}$ ratio (density of active reaction center related to reduction in $\mathrm{Qa}$ ) and the PCM reading, in Sunrise Solo and Golden papaya plants cultivated in a greenhouse. The open circles with reduced PCM readings $(<30)$ refer the senescent 6 th -7 th leaves.

Sunrise Solo

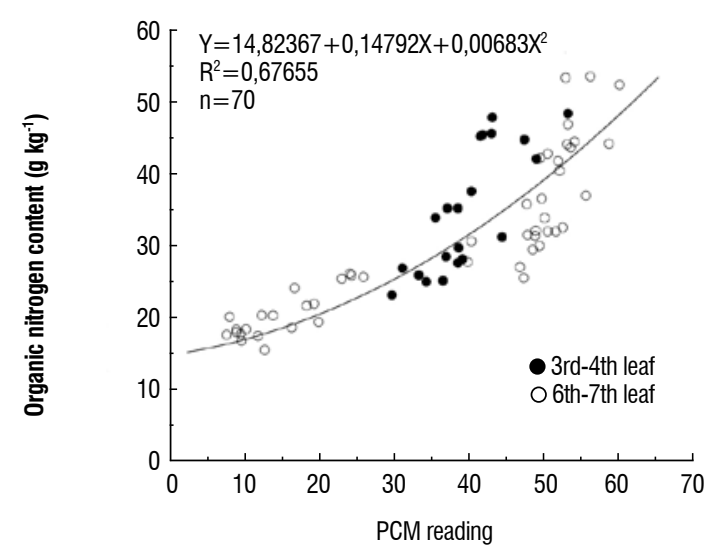

Golden

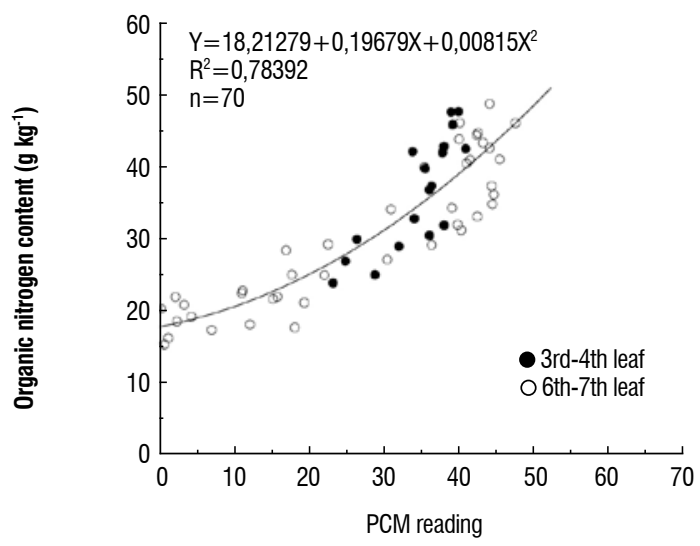

Figure 4. The relation between the organic nitrogen content and the PCM reading, in Sunrise Solo and Golden papaya plants, cultivated in a greenhouse. The open circles with reduced PCM readings $(<30)$ refer the senescent 6 th -7 th leaves. 
'Sunrise Solo' had a statistically reduced decrease (slope $=3.83$ ) in the active reaction centers for this variable compared to 'Golden' (slope =6.23), indicating that 'Golden' had more destruction of the centers with the decrease in the PCM value (Figure 3). Based on these results (Figures 1, 2 , 3) the damage to the PSII structure and activity may be associated with the large quantity of it inactive reaction centers of the senescent older leaves (6th-7th leaves, PCM reading $<25$ ) in the Golden genotype. Actually, the Golden genotype have reduced chlorophyll concentration (Torres-Netto et al., 2009), then the senescence is more fast in this genotype.

Torres Netto et al. (2001) showed that the total nitrogen content fell sharply when the PCM values were lower than 40 in papaya. In the present study, plants hundred DAS had $\mathrm{N}$ deficiency and reduced chlorophyll concentration in older leaves (7th leaf) (Figure 4). An increase in ABS/RC in $\mathrm{N}$ deficient leaves indicates an increase in the antenna size since $A B S / R C$ can be a measure of the relative antenna size (Strasser and Strasser., 1995, Krüger et al., 1997). As pointed out by Lu et al. (2001), the expression ABS/RC (also TRo/ $\mathrm{RC}$ ) refers only to the active PSII reaction centers, thus an inactivation of some PSII reaction centers can lead to an

Sunrise Solo

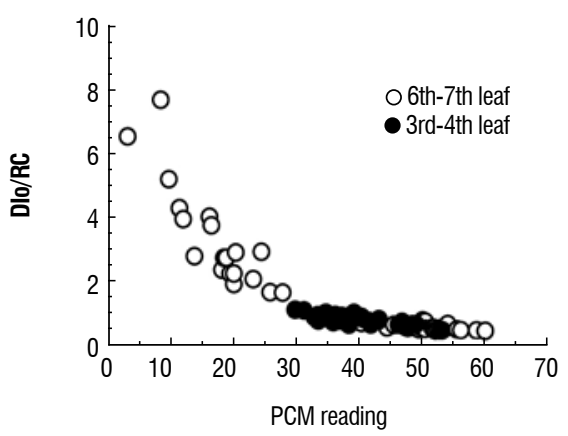

increase in ABS/RC. In rice, Lu et al. (2001) showed that $\mathrm{RC} /$ $\mathrm{CS}$ [quantity of active reaction centers (functional reaction centers)] decreased in the $\mathrm{N}$ deficiency plants.

Because $\mathrm{N}$ is a mobile element, $\mathrm{N}$ deficiency is indicated by chlorosis in the older leaves near the base of the plant. Under severe nitrogen deficiency, these leaves become completely yellow and have very low PCM readings. Younger leaves may not show these symptoms initially, because nitrogen can be mobilized from older leaves (Taiz and Zeiger, 2010). In this experiment, the lower PCM values (Sunrise Solo $<30$; Golden $<25)$ were obtained using senescent older leaves (7th leaf) in plants cultivated after hundred DAS (Figure 4). In maize, $\mathrm{N}$ deficiency increased $\mathrm{ABS} / \mathrm{RC}$ and TRo/RC, however, when the emission of dissipated energy was measured compared to the active reaction centers $\left(\mathrm{DI}_{0} / \mathrm{RC}\right.$ ) (Figure 5), the low PCM values indicated increases in the quantity of dissipated energy (energy not used in photochemistry). This energy is dissipated mainly in the form of heat (Strasser et al,. 2000). Therefore, dissipation can be thought as the absorption of photons in excess which cannot be trapped by the RC. 'Sunrise Solo' showed same sensitive that 'Golden' to increases in dissipated energy.

Figure 5 - Relationship between the $\mathrm{Dl}_{0} / \mathrm{RC}$ ratio (energy dissipated per active reaction center) and the PCM reading, in Sunrise Solo and Golden papaya plants cultivated in a greenhouse. The open circles with reduced PCM readings $(<30)$ refer the senescent 6 th -7 th leaves.

The relationship between $\mathrm{TR}_{0} / \mathrm{CS}_{0}$ (Figure 6) and $\mathrm{ET}_{0} / \mathrm{CS}_{0}$ (Figure 7) and PCM is also an indication of the PSIl structure and activity, and these relationships represent the maximum rate at which an excitation is captured by the reaction center, resulting in a reduction in Qa, measured per cross section unit of the sample, and the re-oxidization of reduced Qa via electron transport per cross section unit of the sample, respectively
(Force et al., 2003). In addition, photosynthetic activity can be expressed by electron transport per leaf cross section (ETo/CS) (Strasser et al., 1999). There was damage to the Qa reduction capacity $\left(\mathrm{TR}_{0} / \mathrm{CS}_{0}\right)$ at $\mathrm{PCM}$ values below 20.0 in 'Sunrise Solo' (Figure 6A) and below 30.0 in 'Golden' (Figure $6 \mathrm{~B})$. However, for the Qa reoxidation capacity $\left(\mathrm{ET}_{0} / \mathrm{CS}_{0}\right)$, the PCM readings were below 30 for 'Sunrise Solo' (Figure 
7A) and 35 for 'Golden' (Figure 7B). When the ET and TR values are expressed per unit cross section, the effect of the reduction in the PCM readings is very evident on the electron transport and capacity of the photosystem to reduce Qa (Figures 6 and 7). In addition, the 'Golden' genotype was more sensitive than 'Sunrise Solo' when PCM readings decrease. In rice, $\mathrm{N}$ deficiency decreased TRo/CS and ETo/CS (Lu et al., 2001). Because the photochemical processes depend on a set of complex protein molecules that are located in and around a highly organized membrane, there is a dependence on the membrane structure. A high degree of organization of the pigment-protein complexes is required for efficient utilization of the solar energy by photosynthetic organisms. Since reduced $\mathrm{N}$ and chlorophyll concentration is often associated with structural membrane damage, it is expected that low PCM values will affect the photochemical efficiency evaluation. Actually, most important in terms of nitrogen content are the thylakoid-bound apoproteins of chlorophyll, mainly light-harvesting chlorophyll binding proteins (LHCP II). Hence, in addition to Rubisco, degradation of LHCP II is a major contributor to the overall loss of protein during foliar senescence (Matile, 1992).
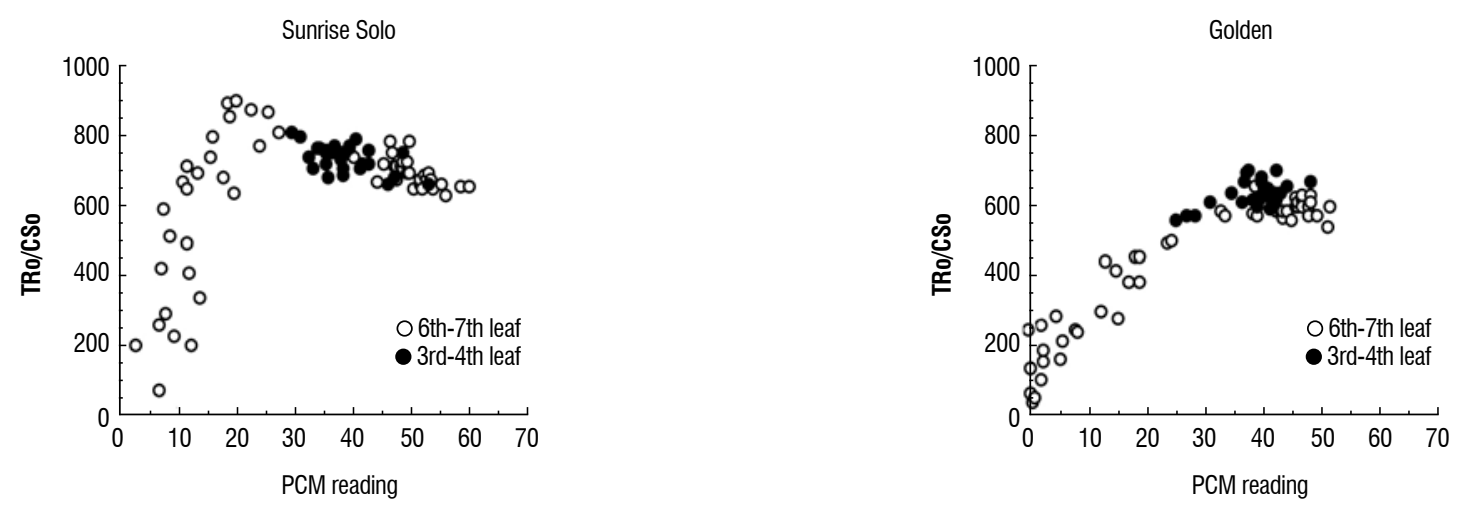

Figure 6. The relation between the $\mathrm{TR}_{0} / \mathrm{CS}_{0}$ ratio quantity of captured energy (reduced Qa) per section of the sample] $(6 \mathrm{~A}, 6 \mathrm{~B})$ and the PCM reading, in Sunrise Solo and Golden papaya plants, cultivated in a greenhouse. The open circles with reduced PCM readings $(<30)$ refer the senescent 6 th -7 th leaves.
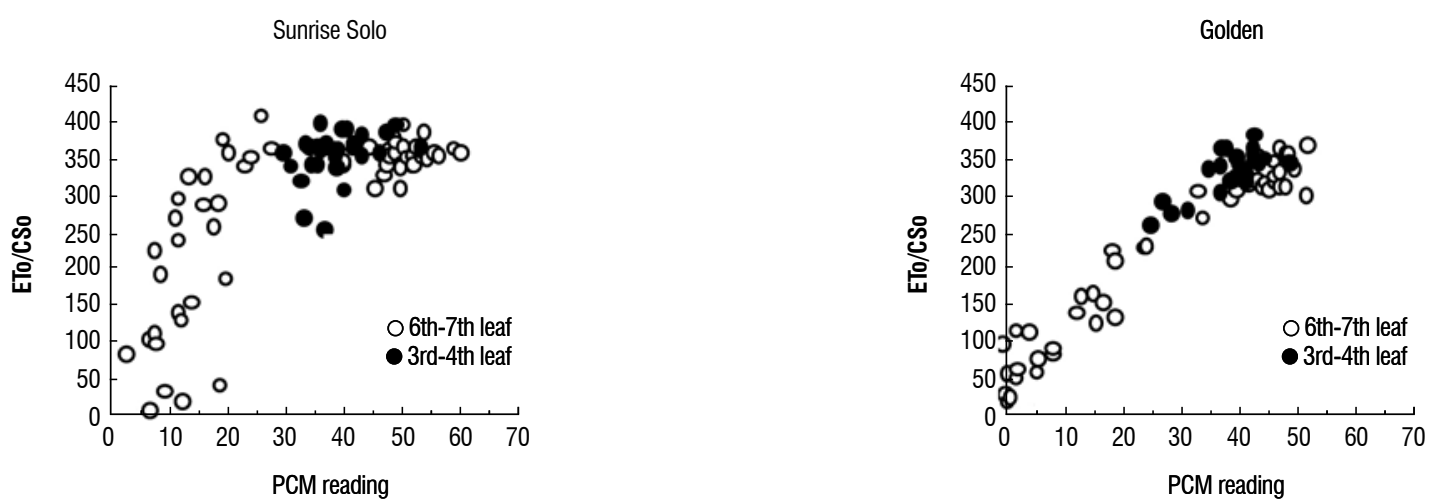

Figure 7. The relation between the $\mathrm{ET}_{0} / \mathrm{CS}_{0}$ ratio (electron transport rate per section of the sample) (7A and 7B) and the PCM reading, in Sunrise Solo and Golden papaya plants, cultivated in a greenhouse. The open circles with reduced PCM readings $(<30)$ refer the senescent 6 th -7 th leaves.

The structure and function of PSII can be visualized by means of the energy pipeline models of the photosynthetic apparatus (Figures. 8A-8D). They are the dynamic models in which the energy fluxes as affected by PCM readings are 
expressed by the width of the corresponding arrows, and the solid and open circles show inactive and active RCs, respectively. Two types of models are proposed. One is the membrane model, which refers to the reaction center in the membrane and thus deals with the specific energy fluxes (per active $\mathrm{RC}$ ). Another is the leaf model, which refers to the cross section of leaf and thus deals with the phenomenological fluxes (per CS). The membrane model demonstrates the antenna size, which corresponds to the value of $A B S / R C$. In the leaf model, the active PSIl reaction centers per cross section (RC/ CS) are indicated by open circles and the inactive ones by closed circles. In Figure 8A and 8C, when the PCM reading was equal to 6.0 for 'Sunrise Solo' and 1.0 for 'Golden', an increase was observed in the absorption per active reaction center (ABS/RC) that was due to the deactivation of some active reaction centers (number of the solid circles). In the leaf model, deactivation of the active reaction centers was indicated by solid circles compared to the open circles (active centers).

The decrease in the PCM value (e.g., 6.0 and 1.0) resulted in a decrease in electron transport, due to the deactivation of the active reaction centers and increased energy dissipation, compared to leaves with greater PCM readings [45 (Sunrise Solo genotype) and 39 (Golden genotype)] (Figures 8B and $8 D$ ). Figures $8 B$ an $8 D$, i.e. 45 and 39 PCM readings, showed that the active reaction centers were not deactivated (only open circles).
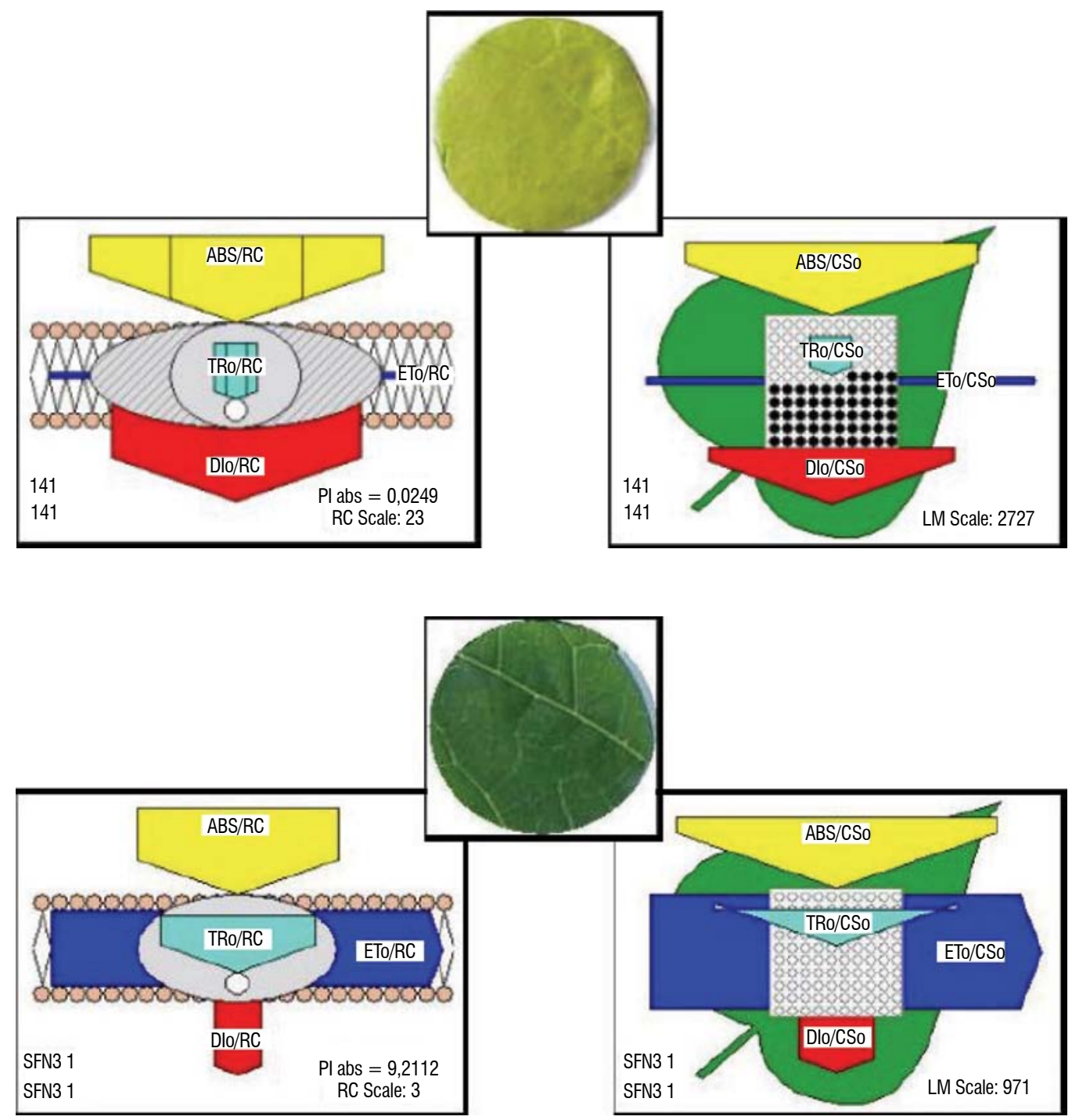

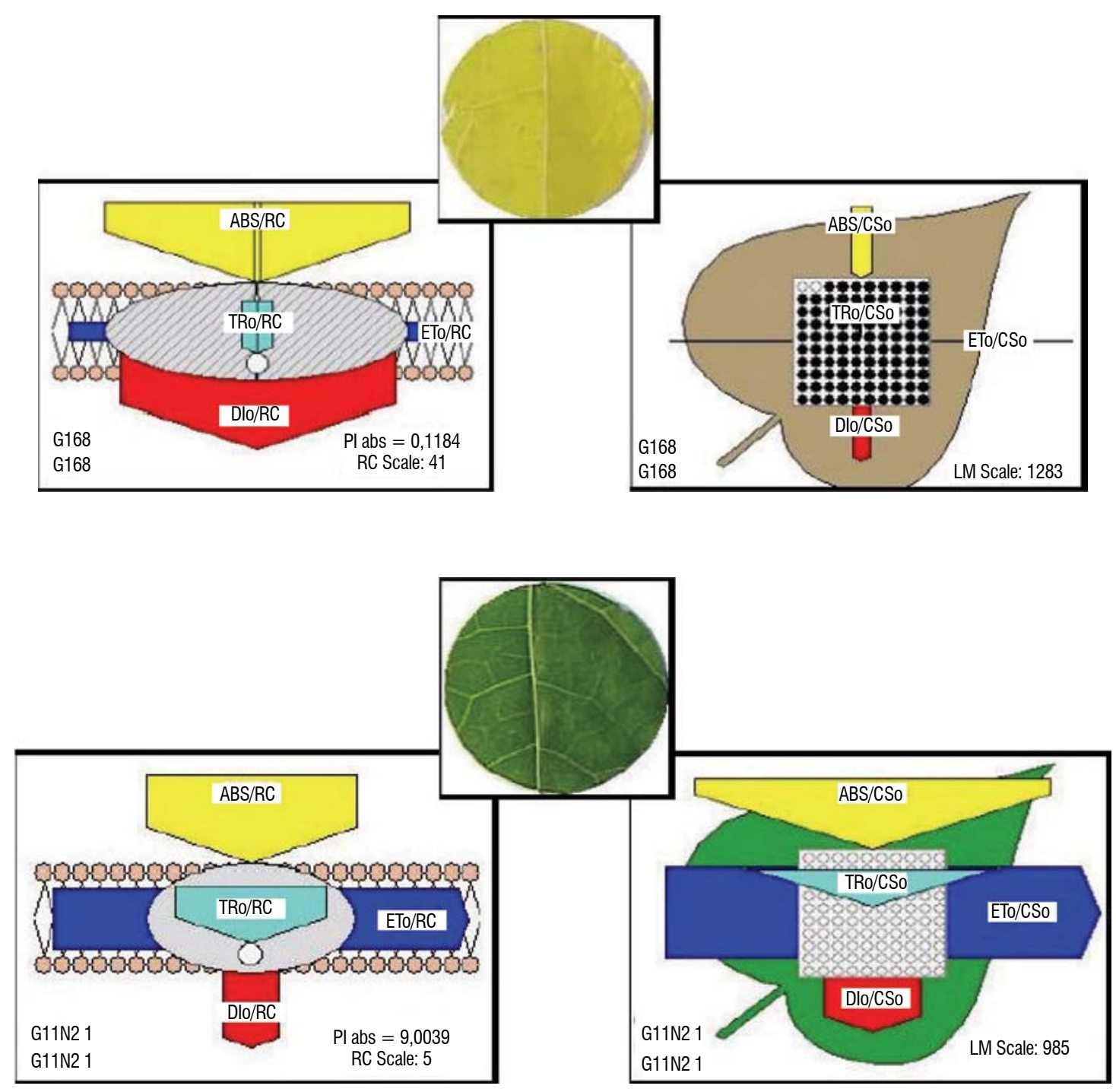

Figure 8. Energy pipeline models of the specific (membrane model, per RC) and phenomenological (leaf model, per CS) fluxes of leaf from a papaya plant of the Sunrise Solo genotype with PCM values of 6.0 (A) and 45 (B), and the Golden genotype with PCM values of 1.0 (C) and 39 (D). The solid and open circles show inactive and active RCs, respectively. The value of each of the parameters can be seen in the relative changes in the width of each arrow.

\section{CONCLUSION}

At PCM values greater than 30 , the assessment of PSIl structure and function were not responsive, indicating that there was no degradation of chlorophyll and a luxury production of these molecules for PCM values greater than 30. For PCM values less than 30 , the PSIl structure length and function was associated with a decrease in the number of active reaction centers. Therefore, in plants 90 and 100 days after sowing, the use of the Biolyzer program (by the JIP-Test) and the Portable Chlorophyll Meter (PCM) were shown to be suitable to assess the photochemical efficiency of the papaya plants of the groups 'Solo'.

Acknowledgments: The authors wish to thank Financiadora de Estudos e Projetos (FINEP), Caliman Agrícola SA, Fundação de Amparo à Pesquisa do Estado do Rio de Janeiro (FAPERJ), Conselho Nacional de Desenvolvimento Científico e Tecnológico (CNPq) and Prof. Dr. Reto Jörg Strasser - Université de Genève for their invaluable assistance 
regarding use of the Biolyzer software. The authors thank CNPq for the fellowships awarded to E. Campostrini. We are also thankful to Dr. David Michael Glenn, USDA-ARSAppalachian Fruit Research Station, Kearneysville, WV 25430 for helpful discussions and grammar correction.

\section{REFERENCES}

Baker NR (2008) Chlorophyll fluorescence: a probe of photosynthesis in vivo. Annual Review Plant Biology 59: 89-113.

Baker NR and Rosenqvist E (2004) Applications of chlorophyll fluorescence can improve crop production strategies: an examination of future possibilities. J. Exp. Bot. 55: 1607-1621.

Bolhàr- Nordenkampf H.R, Long SP, Baker NR, Öquist G, Schreiber U AND Lechner EG (1989) Chlorophyll fluorescence as a probe of the photosynthetic competence of leaves in the field: a review of current instrumentation. Functional Ecology 3: 497 - 514.

Brown SB, Houghton JD, Hendry GAF (1991) Chlorophyll breakdown. In: Scheer H (ed), Chlorophylls, pp. 465- 489. Boca Raton: CRC Press.

Evans J.R. (1989) Photosynthesis and nitrogen relationship in leaves of $C_{3}$ plants. Oecologia, 78: 9-19.

Feller U, Fischer A. (1994). Nitrogen metabolism in senescing leaves. Critical Reviews in Plant Sciences 13: 241-273

Force L, Critchley C AND Van Rensen JJS (2003) New fluorescence parameters for monitoring photosynthesis in plants 1- The effect of illumination on the fluorescence parameters of the JIP-test. Photosynthesis Research 78:17-33.

Hendry GAF AND Price H (1993) Stress indicators: chlorophylls and carotenoids. Methods in comparative plant ecology. London: Chapman and Hall

Hortesteiner, S., Feller, U. (2002) Nitrogen metabolism and remobilization during senescence. Journal of Experimental Botany, 53: 927-937

Jackson, M.L. (1965) Soil Chemical Analysis. New Jersey: Prentice Hall. 498p.

Kapotis G, Zervoudakis G, Salahas G. (2003) Comparison of chlorophyll meter readings with leaf chlorophyll concentration in Amaranthus vlitus: correlation with physiological processes. Russian J. Plant Physiol. 50: 395-397

Krause GH AND Weis E (1991) Chlorophyll fluorescence and photosynthesis: the basics. Annual Review of Plant Physiology and Biology 42: 313-349.

Krüger GHJ, Tsimilli-Michae M, Strasser RJ. (1997) Light stress provokes plastic and elastic modifications in structure and function of photosystem II in camellia leaves. Physiologia Plantarum 101: 265-277.

Kumagai E, Araki T, Kubota F (2009) Correlation of chlorophyll meter readings with gas exchange and chlorophyll fluorescence in flag leaves of rice (Oryza sativa L.) plants. Plant Production Science 12: 50-53.
Lu C, Zhang J, Zhang Q, LI L AND Kuang T (2001) Modification of photosystem II photochemistry in nitrogen deficient maize and wheat plants. Journal Plant Physiology 158: 1423-1430.

Masclaux C, Valadier M-H, Brugiere N, Morot-Gaudry J-F, Hirel B. (2000). Characterization of the sink/source transition in tobacco (Nicotiana tabacum L.) shoots in relation to nitrogen management and leaf senescence. Planta 211: $510-518$

Matile P, Schellenberg M, Peisker C. 1992. Production and release of a chlorophyllcatabolite in isolated senescent chloroplasts. Planta 187, 230235.

Mohammed GH, Binder WD AND Gillies SL (1995) Chlorophyll fluorescence: a review of its practical forestry applications and instrumentation. Scandinavian Journal Forest Research 10: $383-410$.

Scholes JD AND Horton P (1993) Photosynthesis and chlorophyll fluorescence: simultaneous measurements. In: Hendry GAF AND Grime JP (eds), Methods in comparative plant ecology: a laboratory manual., p. $130-$ 135. London: Chapman and Hall.

Schreiber US, Bilger W, Hormann H AND Neubauer C (1998) Chlorophyll fluorescence as a diagnostic tool: basics and some aspects of practical relevance. In: Raghavendra AS (ed), Photosynthesis: a comprehensive treatise, p.320-336. Cambridge University.

Strasser RJ, Tsimilli- Michael M AND Srivastava A (2000) The fluorescence transient as a tool to characterize and screen photosynthetic samples. In: Yunus M, Pather U, Mohanly P (eds.), Probing Photosynthesis: Mechanisms, Regulation and Adaptation, p.445-483.Taylor and Francis, London.

Strasser RJ, Srivastava A, Tsimilli-Michael M (1999) Screening the vitality and photosynthetic activity of plants by fluorescence transient. In: Behl RK, Punia MS, Lather BPS (eds), Crop improvement for food security, pp. 79126. SSARM, Hisar.

Strasser BJ AND Strasser RJ (1995) Measuring fast fluorescence transients to address environmental questions: the JIP- Test. In: Mathis P (ed.), Photosynthesis: from light to biosphere, p.977 - 980. The Netherlands: Kluwer academic publishers.

Taiz L AND Zeiger E (2010) Plant Physiology. Sinauer Associates, Inc., Publishers, Sunderland, Massachusetts. 782p.

Torres Netto A, Campostrini E, Oliveira JG, Yamanishi OK (2002) Portable chlorophyll meter for the quantification of photosynthetic pigments, nitrogen and possible use for assessment of the photochemical process in Carica papaya L. Braz. J. Plant Physiol. 14: 203-210

Torres Netto A, Campostrini E, Azevedo L da Costa, Souza MA, Ramalho, JC, Chaves, MM (2009) Morphological analysis and photosynthetic performance of improved papaya genotypes. Braz. J. Plant Physiol. 21: 209-222

Wellburn AR (1994) The spectral determination of chlorophyll a and b, as well as total carotenoids, using various solvents with spectrophotometers of different resolution. J. Plant Physiol. 144: 307-313. 